Institutional Changes and their Impacts on the Province of São Paulo: the Economy of São Paulo in Face of the Political Centralization of the Brazilian Empire (1835 - 1850)

\title{
Mudanças Institucionais e seus impactos na província de São Paulo: a economia paulista ante a centralização política do Império brasileiro (1835 - 1850)
}

\section{Vinícius de Bragança Müller e Oliveira}

Bacharel em história pela Pontifícia Universidade Católica de São Paulo e Mestre em Economia pela Universidade Estadual Paulista Julio de Mesquita Filho.

\begin{abstract}
Resumo
As mudanças institucionais que ocorreram durante as décadas de 30 e 40 do século XIX no Brasil precipitaram, para muitos autores, uma excessiva centralização do poder nas mãos do governo imperial, em detrimento dos poderes das províncias. 0 artigo apresenta alguns números da economia paulista durante os anos de 1835 e 1850 para refutar a hipótese de falência e, conseqüentemente, da dependência das províncias em relação ao governo imperial, mostrando as possibilidades que São Paulo teve para manter seus orçamentos equilibrados e sua economia agrícola em crescimento.
\end{abstract}

\begin{abstract}
For many authors, the institutional changes that happened during the 1830s and 1840s in Brazil were responsible for an excessive centralization of the political power in the hands of the imperial government, harmful to provincial autonomy. This article presents some data of the economy of São Paulo between 1835 and 1850 to refute the hypothesis of failure and, thus, the dependence of the provinces towards the imperial government, showing that in São Paulo it was possible to maintain the provincial finances balanced and the agricultural economy constantly growing.
\end{abstract}

\section{Palavras-chave}

economia, América portuguesa / Brasil, Império do Brasil, história econômica

\section{Keywords}

economy, Portuguese America / Brazil, Brazilian Empire, economic history 


\section{Introdução}

As dificuldades acerca da construção do Estado brasileiro nos abrem a possibilidade de pesquisas e análises que podem transitar em várias áreas, entre elas aquela que entrelaça a História e a Economia.

0 trabalho aqui exposto apresenta algumas discussões vinculadas à História Econômica, entre as muitas que ajudam a explicar as tramas que precipitaram, no Brasil imperial, a combinação entre centralismo e poderes locais, com destaque à questão dos recursos fiscais e o desenvolvimento econômico da província de São Paulo sob a luz das reformas ocorridas nas décadas de 30 e 40 do século XIX. Isso porque, além da nada usual situação de uma monarquia que não tinha monarca - Dom Pedro abdicara em abril de 1831 e seu filho, Pedro II, contava com apenas 5 anos - , as instituições do então jovem país ainda não estavam formadas, estimulando o aparecimento de discordâncias no que tange o grau de autonomia das províncias ante o poder do Estado Nacional.

Portanto, as reformas que buscavam um possivel equilibrio entre os poderes provinciais e o poder central nos servem como o arcabouço que possibilita perceber a ascensão da economia paulista durante a década de 40 do século XIX.

0 que a pesquisa buscou analisar foi a relação - se existiu, de fato, uma - entre as reformas institucionais concernentes à centralização e descentralização e os orçamentos provinciais paulistas entre os anos de 1835 e 1850. Para tanto, algumas fontes primárias foram de fundamental importância, tais como os Diários da Tesouraria Provincial e os Relatórios dos Presidentes de Província e os Mapas de Exportação do porto de Santos, entre outras. Também buscou verificar o desenvolvimento econômico da província paulista, com destaque à produção e exportação agrícola.

0 primeiro item apresentará uma mais cuidadosa discussão bibliográfica com os comentários sobre algumas obras que tratam da economia e política imperial, apontando concordâncias e discordâncias e propondo algumas interpretações alternativas.

Já o segundo item apresenta as fontes que discutem a relativa autonomia paulista durante o período de centralização no que se refere às questões orçamentárias. Desta maneira, o capitulo destaca o crescimento da economia cafeeira paulista em um ambiente no qual se acreditou que o governo central detinha praticamente toda a decisão de investimento, sobrando pouco às províncias. Por mais que seja impossivel negar a centralização das decisões políticas e administrativas em mãos do governo imperial, era possível à província paulista manter relativa autonomia em suas decisões, inclusive no que tange as questões legislativas e orçamentárias.

\section{1. $\mathbf{O}$ debate sobre a autonomia fiscal das províncias no Império brasileiro}

Entre os debates acerca do funcionamento do período monárquico no Brasil, destaca-se aquele referente à disputa entre a tendência centralizadora e a descentralizadora que permeou a época. Tal embate consumiu décadas de discussões entre aqueles que acreditavam que a descentralização poderia organizar melhor um pais de proporções continentais, garantindo relativa autonomia às provincias; e aqueles que temiam a dispersão da unidade monárquica - e mesmo sua existência - se o arcabouço legal do país não garantisse a centralização administrativa e política. Dessa forma, desde, ao menos, a independência de 1822, esta questão e seus resultados 
Essa combinação pode ser definida, em linhas gerais, pelo arranjo institucional que garantia um compromisso das elites regionais com o poder central, criando uma situação muito próxima ao federalismo.

As mudanças institucionais ocorridas no periodo regencial marcaram toda a posterior discussão político-partidária do Império. As duas tendências políticas que se seguiram à aprovação do Ato Adicional de 1834 -regressista e a progressista - deram origem, respectivamente ao Partido Conservador e ao Partido Liberal, dominantes até a queda da Monarquia em 1889.

IGLÉSIAS, Francisco. Política unitária do Segundo Reinado. Revista de Ciências Econômicas da Universidade de Minas Gerais. Ano 4, nº 8, p. 38, jul-dez 1955.

Ibidem, p. 39. acabaram por definir - em contraste com os países hispano-americanos - a adoção da monarquia unitária no Brasil, sinalizando que a estrutura imperial seria centralizada se comparada com o republicanismo dos vizinhos. Não obstante a permanência de "ilhas" de tendência republicana durante todo o período imperial, apenas no final do século XIX, e com mais eloqüência a partir da década de 1870, a opção descentralizadora e republicana ganhou espaço suficiente para se tornar bandeira do movimento que culminou na queda do Império em 1889.

Mesmo assim, muitos defenderam a adoção de medidas descentralizadoras sem questionar a monarquia, idéia que, ao ser praticada, gerou uma situação conhecida como "experiência republicana do Império"1. Foi nesse periodo, marcado pela espera da maioridade do Imperador Pedro II, que se deu essa combinação entre monarquia e experiência republicana. Dessa forma, o período regencial - como é conhecido - fundou-se com a abdicação de Pedro I em 1831 e se caracterizou pela provisoriedade que deveria ter, já que o herdeiro do trono, Pedro de Alcântara, só não assumira imediatamente o posto porque contava, à época, com apenas 5 anos. 0 periodo regencial se estendeu de 1831 até 1840, quando o novo Imperador, ainda com 14 anos, foi coroado no episódio conhecido como Golpe da Maioridade.

Porém, mesmo findando em 1840, os debates e medidas tomadas durante a Regência conformaram a discussão que se prolongou por boa parte do período imperial. ${ }^{2}$ Foi nesse contexto de espera pela maioridade do futuro Imperador que o debate acerca da centralização ou descentralização viveu seus dias mais intensos, dada a percepção, por boa parte da sociedade brasileira, que o perigo da re-colonização portuguesa - atribuida por muitos a D. Pedro I - havia terminado no 07 de abril. Polêmicas sobre tal perigo à parte, o fato é que a Constituição outorgada em 1824 pelo Imperador mostrava claros sinais absolutistas e, portanto, centralizadores que, com a abdicação, poderiam ser questionados. Além disso, a saída de D. Pedro I precipitava a possibilidade de discussão acerca da estrutura administrativa que receberia Pedro II quando se tornasse Imperador, estimulando a disputa política e ideológica entre tendências que começavam a se afirmar.

A definição de tais tendências se fez através dos liberais e dos conservadores, sendo defensores da descentralização e da centralização, respectivamente. Após alguns anos de indefinições iniciais, em 1834, a promulgação do Ato Adicional à Constituição de 1824 aparentava ser a "vitória" dos liberais, já que adotava medidas inegavelmente descentralizadoras quanto à divisão de funções entre o governo Imperial (ou central) e as províncias. Apenas seis anos depois, com a Lei de Interpretação ao Ato Adicional, é que a tendência centralizadora voltou a "dar as cartas" no país.

Mas, o que afinal, aconteceu nesses seis anos que modificou de tal maneira a paisagem política do país? Não é fácil responder, mas uma análise mais detalhada sobre o Ato de 1834 e suas conseqüências, assim como sobre eventos da época, podem apontar alguns caminhos.

0 Ato de 1834, mesmo sendo representante maior do "avanço liberal" e, portanto, da tendência à descentralização administrativa e política trouxe, na prática, mais problemas que soluções às províncias. É assim que Iglésias ${ }^{3}$ (1955: 38) vê tal situação, já que enxerga no Ato Adicional brechas para a continuidade da centralização as quais foram alargadas por meio da Lei de Interpretação do Ato Adicional de 1840. Diz ainda que, o fato de os Presidentes de Províncias serem nomeados pelo Imperador limitava qualquer tentativa de autonomia provincial. 4 
FERREIRA, Gabriela Nunes. Centralização e descentralização. 0 debate entre Tavares Bastos e visconde de Uruguai. São Paulo: Ed. 34, 1999. p.28-29.

6

SOUZA, Otávio Tarquínio de. Bernardo Pereira de Vasconcelos. São Paulo:Edusp, 1988. p.162.

DEVEZA, Guilherme. Política tributária no periodo Imperial. In: HOLANDA, Sérgio Buarque de; CAMPOS, Pedro Moacyr de (orgs.). História Geral da Civilização Brasileira. Tomo II - 0 Brasil Monárquico, Vol. 4. São Paulo: Difusão Européia do Livro, 1972. p.67.

8

Ibidem. p. 67.
De maneira um pouco diversa, Ferreira ${ }^{5}$ avalia o Ato Adicional como algo "que veio dar novo contorno à organização política e administrativa do Império", assim como acredita que "as Províncias ganharam vida nova, não mais como simples unidades administrativas, mas sim políticas, com significativa margem de autonomia - muito embora tenha-se mantido a nomeação dos presidentes de província pelo Imperador." Essa discussão sobre o alcance das medidas descentralizadoras de 1834 ganha força quando ouvimos um personagem influente da política nacional da época, o mineiro Bernardo Pereira de Vasconcelos, citado por Souza 6 , em uma de suas falas mais significativas:

Fui liberal; então a liberdade era nova no país, estava nas aspirações de todos, mas não nas leis; o poder era tudo: fui liberal. Hoje, porém, é diverso o aspecto da sociedade; os princípios democráticos tudo ganharam, e muito comprometeram; a sociedade, que então corria risco pelo poder, corre agora risco pela desorganização e pela anarquia. Como então quis, quero hoje servi-la, quero salvá-la; e por isso sou regressista. Não sou trânsfugo, não abandono a causa que defendo, no dia de seus perigos, de sua fraqueza; deixo-a no dia em que tão seguro é seu triunfo que até $o$ excesso a compromete.

Vasconcelos, tudo indica, atribuía ao Ato Adicional - do qual ele mesmo foi um dos redatores, embora tenha confessado, após a promulgação sua discordância em relação ao texto final - um perigo para a manutenção da ordem no país. Portanto, deve-se acreditar que Vasconcelos, mesmo com as limitações que Ihe atribuía, depositava sobre o Ato de 1834 o papel descentralizador do qual havia se originado.

De fato, se levarmos em conta duas das atribuições legadas às províncias pelo Ato Adicional, podemos concordar que, mesmo com as limitações anunciadas por Iglésias, ele contribui para a descentralização administrativa e política do Império: a) a prerrogativa de fixar receitas e despesas provinciais, incluindo a possibilidade de criar impostos; e b) de legislar sobre a criação, supressão e nomeação para os empregos municipais e provinciais, e estabelecimento de seus ordenados. Tais direitos, com certeza, alteravam o orçamento das províncias, e, por conseqüência, do governo central.

Deveza7, em seu artigo sobre a política fiscal do Império, vê na lei de 24 de outubro de 1832 - portanto, dois anos antes do Ato Adicional - a primeira vez que se distinguem as receitas "Gerais" e as receitas "Provinciais", destacando que "a receita provincial limitou-se a dizer que the pertenciam todos os impostos ora existentes não compreendidos na receita geral". E finaliza, 8 referindo-se já ao Ato Adicional de 1834:

\footnotetext{
(Às Províncias) Era-Ihes defeso, porém, legislar sobre os impostos de importação. Mas o certo é que, não obstante a autonomia politica outorgada às provincias, bem restrito continuou o âmbito de ação, no setor tributário, de suas Assembléias legislativas, uma vez que as leis orçamentárias anteriores ao Ato Adicional já haviam assente o que pertencia à Receita Geral e que representava quase tudo quanto vinha sendo taxado nos diferentes ramos de atividades.
}

Pode-se complementar tal informação, afirmando que era vedada também a tributação suplementar sobre o mesmo fato, restando poucos tributos para garantir uma receita adequada às necessidades das províncias. Vale destacar que aqui se usa a palavra "também" porque se consideram os impostos de importação como sendo exclusivos do governo central. $\mathrm{Na}$ verdade, ao se fazer tal consideração acerca dos impostos sobre impor- 
TAVARES BASTOS, Aureliano Cândido. A Província: estudo sobre a descentralização no Brasil. Brasilia: Senado federal, 1996. (1 Edição: 1870). p. 338.

\section{0}

DINIZ, Adalton Franciozo. Centralização política e apropriação de Riqueza: análise das finanças do Império Brasileiro (1821 - 1889). 2002 245f. e anexos. Tese (Doutorado). Faculdade de Filosofia, Letras e Ciências Humanas, Universidade de São Paulo. São Paulo, 2002. p. 80.

11

Ibidem, p. 157.

\section{2}

FERREIRA, Gabriela Nunes. Centralização e descentralização. 0 debate entre Tavares Bastos e visconde de Uruguai. São Paulo: Ed. 34, 1999. p. 98.

13

DINIZ, Adalton Franciozo. Op.Cit. p. 202. tação, está se reproduzindo a afirmação de Tavares Bastos ${ }^{9}$, um dos mais destacados defensores da descentralização imperial:

Nos paises de governo descentralizado há porventura uma regra absoluta, um critério seguro, para definir em todos os casos o caráter nacional ou local de certos impostos? Alguns, o de importação, por exemplo, têm evidentemente o cunho dos interesses do pais inteiro.

No mesmo sentido, e com algumas considerações relevantes, Diniz ${ }^{10}$ afirma que:

0 comércio de importação, dada a facilidade com que era tributado e o volume de rendimento que podia produzir, constituia uma das principais fontes de recursos dos governos no século XIX(...). No Brasil a circunstância não era diferente, mas o Tratado de Comércio restringiu, em tese, o volume da receita que o Governo poderia extrair dessa fonte.

E completa ${ }^{11}$, citando o artigo 12 do Ato Adicional:

A liberdade para as províncias criarem impostos, todavia, não era plena, pois o Ato Adicional vedava às Assembléias Provinciais a criação de tributos que prejudicassem as imposições do Governo Geral e também não Ihes era permitido legislar sobre impostos de importação.

Dessa forma, Diniz confirma aquilo que afirmou Deveza, mostrando com clareza a importância dos impostos sobre importação no orçamento nacional e a exclusividade desta prerrogativa sob o governo central.

De fato, não existia nenhuma lei que garantisse às Províncias arrecadação de impostos sobre importação, principal fonte tributária do país.

Eis, então, um ponto sobre o qual a literatura já produzida é quase unânime: as Províncias, sem os direitos sobre importação, não participavam da melhor e mais rentável "fatia do bolo" fiscal, resultando na péssima situação financeira que enfrentaram após a tendência descentralizadora se afirmar a partir do Ato Adicional. Novamente, Ferreira12, que, em sua dissertação de Mestrado analisa o debate entre centralização e descentralização no Império a partir de dois dos mais destacados defensores das duas tendências - Visconde do Uruguai e Tavares Bastos, respectivamente -, escreve:

Sobre um ponto os dois autores concordam: a divisão de rendas que prevalece desde a lei orçamentária de 31 de outubro de 1835 deixou as províncias - que assumiram uma série de novos encargos a partir do Ato Adicional - em precária situação financeira. De fato, é sabido que ao governo geral coube a 'parte do leão' da matéria tributável, particularmente os impostos de importação e exportação.

Dessa forma, evidencia-se que, mesmo no periodo de "avanço" liberal, a situação econômica das províncias era de penúria. 0 que se questiona, nesse artigo, é a) a incapacidade das províncias gerarem seus próprios recursos; e b) a quase inexistente autonomia provincial em manejar seus recursos e, c) a precária situação econômica vivida pelas províncias. Vejamos o que afirma Diniz ${ }^{13}$ :

Com efeito, os dados do Balanço demonstram que, a partir da década de 1830, a estrutura financeira do Império funcionou eficientemente no processo de apropriação da renda produzida nas provincias, principalmente Pernambuco, Bahia, Maranhão, Pará, São Paulo e Rio de Janeiro. Em conjunto, essas províncias forneceram 126,65 
milhões de libras em tributos ao Império e receberam 58,70 milhões de libras sob a forma de recursos nelas despendidos; a diferença em favor do Governo Geral foi, portanto, de 67,95 milhões de libras. (...) Mas, além do caso dessas províncias que forneceram recursos sistematicamente ao Governo Geral, aquelas províncias mais carentes, caso aumentassem o volume de impostos gerados, também teriam parte de sua renda remetida para a sede do poder central do Império.

Pois bem, podemos a partir de tal afirmação concluir que o problema das províncias não era a inexistência de recursos, e sim a transferência desses recursos ao governo central através da tributação que, quase toda, ficava a cargo deste. Desse modo se confirmaria a estrutura altamente centralizada a qual associamos o Império Brasileiro. Vejamos, portanto, como a economia da província de São Paulo se comportou durante o período e se tal comportamento confirma a hipótese de fraqueza provincial frente a um governo central que sofria de gigantismo.

\section{A economia paulista entre 1835 e 1850 .}

\subsection{Receitas e despesas}

São conhecidos e variados os estudos que tentaram estabelecer a divisão de rendas entre o governo central do Império e as províncias, de tal maneira que entre todos eles, nenhum apresenta exatamente o mesmo resultado. Isto se deve ao fato que, muitas vezes, aquilo que era de direito tributável, não o era de fato; e, ao contrário, muitas brechas na lei eram usadas para garantir uma tributação que não estava prevista. Por exemplo, os argumentos referentes aos direitos de exportação e importação - tão importantes, como vimos - eram usados de maneira que, quando defendidos por aqueles que gritavam por uma maior autonomia das províncias, a taxação sobre produto importado e redistribuido nas regiões nacionais não era considerada direito sobre importação. Em outros termos, como os impostos sobre importação eram definidos como sendo competência do governo central e não das províncias, mas não era claramente definido o que se considerava importação, era possivel driblar tal definição e, muitas vezes, bi-tributar algum produto. Se um produto importado chegasse ao porto do Rio De Janeiro e de lá fosse distribuido em Minas Gerais era possivel cobrar direitos sobre este produto na travessia entre uma província e outra. Esse imposto seria de competência da província, e não do governo central. Porém, mesmo os autores apresentando diferenças em suas definições sobre as competências, algumas são comuns e parecem constituir uma base regular de tributação nas províncias.

Um trabalho que tentou definir e, assim acabar com as diferenças

14

TESSITORE, Viviane. As fontes da riqueza pública. Tributos e administração tributária na Província de São Paulo (1832 - 1892). 1995. 395f. Dissertação (Mestrado). Faculdade de Filosofia, Letras e Ciências Humanas, Universidade de São Paulo, São Paulo, 1995. p. 69. apresentadas por diversos autores é o de Tessitore ${ }^{14}$, usado aqui como referência. Nele, a autora afirma:

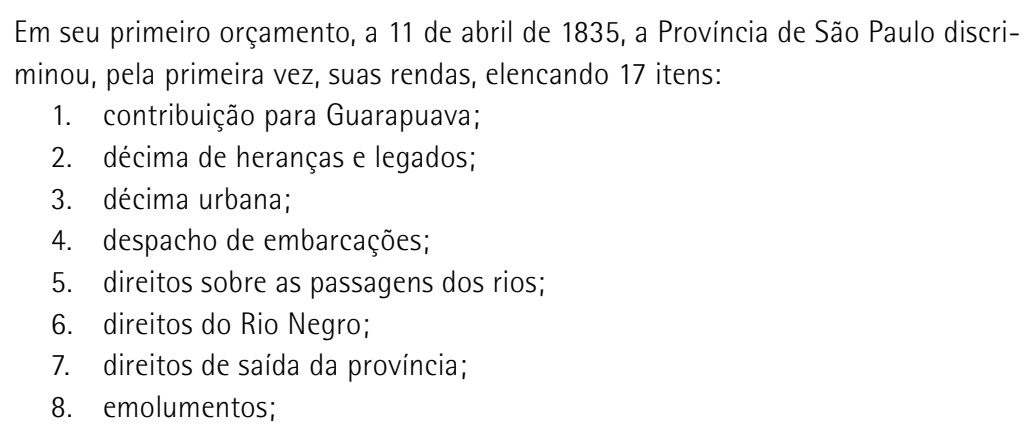


9. imposto sobre aguardentes;

10. imposto sobre casas de leilão e moda;

11. imposto sobre reses mortas;

12. meia sisa sobre venda de escravos;

13. novo imposto sobre os animais em Sorocaba;

14. novo imposto sobre armazéns, tabernas e botequins;

15. novos e velhos direitos provinciais;

16. subsídio literário;

17. taxa de barreira

É importante lembrar que esta pesquisa não tem como objetivo definir as rendas provinciais em todas as suas competências. 0 que se busca é perceber que, mesmo com todas as mudanças relativas à centralização e descentralização e as dificuldades - fossem legais ou orçamentárias - das províncias, era possivel a elas conseguir arrecadação suficiente para, em muitos casos, manter seus orçamentos e investimentos. No caso de São Paulo, como veremos, esta parece ser a situação, independente de estar vivendo o período definido pelo Ato Adicional de 1834 e, portanto, pelas tentativas de garantia de maior autonomia às províncias ou no período da centralização. Basta, como sintese, que se afirme a possibilidade das províncias em taxar importações e exportações que circulassem em seus territórios pela falta de definição clara do que era considerado importado e exportado.

Sendo isso possivel, estas rendas estariam garantidas às províncias através de vários impostos. $E$, no caso de São Paulo, através, principalmente, das taxas de barreiras e dos direitos de saída, incluidos no rol das rendas provinciais. ${ }^{15}$ Isso porque as taxas de barreiras respondiam por aproximada-

As taxas de barreiras incidiam sobre o trânsito de animais e pessoas nas estradas, e os direitos de saída sobre as exportações. No caso dos direitos de saída (dízimos provinciais), cabia à província uma parcela daquilo que era arrecadado, sendo a outra de direito do governo geral.

\section{6}

TESSITORE, Viviane. As fontes da riqueza pública. Tributos e administração tributária na Província de São Paulo (1832 - 1892). 1995. 395f. Dissertação (Mestrado). Faculdade de Filosofia, Letras e Ciências Humanas, Universidade de São Paulo, São Paulo, 1995. p. 70. mente metade das receitas de São Paulo se somadas aos direitos de saída. Novamente, vejamos o que diz, sobre isso, Tessitore ${ }^{16}$ :

\begin{abstract}
Dois tributos ocuparam imediatamente a atenção dos legisladores provinciais e a eles se deu pronta regulamentação: os direitos de saída da provincia e as taxas de barreiras. É fácil entender o porquê disso apenas observando sua arrecadação em relação aos demais; representavam quase $50 \%$ da receita provincial. Ambos foram os pilares da arrecadação em São Paulo, a taxa de barreira substituída, nas décadas de 1870 e 1880 pelo imposto de trânsito. Não poderia ser diferente numa economia baseada na agricultura e na exportação, atividades que só cresceram em importância ao longo do século XIX, e para as quais a questão dos caminhos que permitissem a rápida e segura circulação da produção era fundamental. Só rivalizaram com eles em renda produzida os impostos sobre trânsito de animais - em primeiro lugar, os direitos de Rio Negro, depois o novo imposto sobre animais em Sorocaba.
\end{abstract}

Ou seja, os direitos de saída e taxas sobre trânsito de animais, se somados, apresentavam a maior parte da arrecadação da província (ver tabela IV). Portanto, se a situação financeira das províncias - como afirmada por quase toda a literatura - era precária devido à exagerada centralização nas mãos do governo, para São Paulo, era imprescindivel que as rendas obtidas com estes dois impostos (direitos de saída e trânsito de animais) fossem cada vez maiores. Para tanto, era necessário que a província construisse um mecanismo que possibilitasse a reprodução e aumento destas rendas, que representavam, como se viu, uma parcela muito grande do total arrecadado. Tal processo dependia, por sua vez, de uma atenção maior aos investimentos públicos para que gerasse maior capacidade fiscal, fosse pelo controle, fosse por facilitar a circulação de mercadorias e animais, inclusive garantindo o acesso de muitas delas aos portos. Então, estava na mão da província, através das respectivas Assembléias Legislativas e de sua 
capacidade de organização da fiscalização, a maior parte da definição dos investimentos e das rendas obtidas. Vale a ressalva que foi durante a década de 1840 que a produção e exportação de café paulista ganhou o destaque que pôde garantir o aumento da arrecadação e dos investimentos. Além disso, também vale destacar que São Paulo era - e geograficamente ainda é - passagem obrigatória daqueles que iam do sul do país a Minas Gerais e ao Rio de Janeiro e vice-versa; portanto sendo privilegiado na cobrança sobre o trânsito de animais. Em outros termos, se os dois impostos eram responsáveis por grande parte da arrecadação paulista, assim como sua produção e exportação de café apresentaram resultados positivos expressivos durante a década de 1840, o crescimento da economia de São Paulo e conseqüentemente o equilibrio de seu orçamento eram, quase que exclusivamente, de responsabilidade local, independendo das regras do governo central. Vejamos, a partir dos dados quantitativos, os indícios que podem nos levar por esses caminhos e, desta forma, chegarmos a tais conclusões.

\section{Tabela I}

Receita e despesa da província de São Paulo, em mil réis:

\begin{tabular}{|c|c|c|}
\hline Anos & Receita & Despesa \\
\hline $1835-36$ & $292: 720 \$ 359$ & $171: 323 \$ 607$ \\
\hline $1836-37$ & $338: 289 \$ 390$ & $208: 145 \$ 337$ \\
\hline $1837-38$ & $436: 404 \$ 153$ & $285: 791 \$ 421$ \\
\hline $1838-39$ & $315: 903 \$ 550$ & $306: 708 \$ 441$ \\
\hline $1839-40$ & $430: 728 \$ 169$ & $411: 828 \$ 239$ \\
\hline $1840-41$ & $326: 429 \$ 787$ & $203: 086 \$ 924$ \\
\hline $1841-42$ & $405: 418 \$ 878$ & $679: 267 \$ 035$ \\
\hline $1842-43$ & $292: 913 \$ 824$ & $363: 078 \$ 524$ \\
\hline $1843-44$ & $327: 312 \$ 143$ & $270: 617 \$ 626$ \\
\hline $1844-45$ & $408: 516 \$ 055$ & $586: 813 \$ 178$ \\
\hline $1845-46$ & $574: 138 \$ 548$ & $585: 852 \$ 322$ \\
\hline $1846-47$ & $706: 223 \$ 325$ & $615: 132 \$ 335$ \\
\hline $1847-48$ & $571: 828 \$ 132$ & $503: 324 \$ 220$ \\
\hline $1848-49$ & $431: 746 \$ 032$ & $451: 459 \$ 038$ \\
\hline $1849-50$ & $457: 922 \$ 434$ & $523: 608 \$ 625$ \\
\hline $1850-51$ & $489: 531 \$ 136$ & $503: 759 \$ 530$ \\
\hline
\end{tabular}

Fonte: COSTA, Hernani Maia. As barreiras de São Paulo: Estudo Histórico das barreiras paulistas no século XIX. São Paulo, 1984. FFLCH/USP (dissertação de mestrado).

Observa-se, pela tabela, que as nuances relacionadas à centralização ou descentralização não estabeleceram uma relação positiva com as receitas paulistas. A receita do ano orçamentário de 1836-37, no auge das medidas descentralizadoras, não é maior que a do ano de 1846-47, quando o "regresso" conservador e, por conseqüência, a centralização já haviam se consolidado.

Pode-se perceber da tabela referente às receitas e despesas da provincia paulista que, nos 16 exercícios revelados, 9 apresentaram superávit, enquanto outros 7 apresentaram déficit. Mesmo assim, somados os déficits dos orçamentos de 1841-42 e 1842-43, obtém-se um resultado maior que se feito o mesmo com todos outros 5 anos orçamentários que também apresentaram déficits. Vale lembrar que 1842, além da onda de revoltas de caráter liberal que tomou conta de parte da província, ocorreram geadas que diminuíram sensivelmente a produção agrícola, comprometendo, portanto, a cobrança sobre os direitos de saída além de precipitar gastos maiores para a recuperação de regiões atingidas. 
PIVARO, Hilda. 0 processo de recuperação da economia paulista (1765 - 1850). 1985. 3 vols. Tese (Doutorado). Faculdade de Filosofia, Letras e Ciências Humanas, Universidade de São Paulo, São Paulo, 1985. p.113.

18

Relatório do presidente da provincia de São Paulo, Pires da Mota, 1843.

19

COSTA, Hernani Maia. As barreiras de São Paulo: Estudo Histórico das barreiras paulistas no século XIX. 1985. 243f. Dissertação (Mestrado). Faculdade de Filosofia, Letras e Ciências Humanas, Universidade de São Paulo, São Paulo, 1985.
Assim afirmou Pivaro17:

É interessante observar que no exercicio de 1842-43, as exportações de chá e café estiveram em declínio, aliás, os índices mais baixos de ambos os produtos, em conseqüência das geadas ocorridas na área paulista.

0 que é confirmado pelo presidente da provincia, Pires da Mota:

A diminuta exportação no ano que consta o mapa pelo que respeita aos gêneros - açúcar e café - deve-se um tanto atribuir, não somente ao dano ocasionado pela geada, em alguns pontos, que sofreu a província; mas também ao movimento de rebelião que na mesma se desenvolveu em maio de $1842 .{ }^{18}$

Como se sabe, o ano fiscal ia de $1^{\circ}$ de julho a 30 de junho do ano seguinte. Portanto, a revolta de maio de 1842, citada por Pires da Mota, causou impacto ainda no orçamento de 1841-42, enquanto a geada atingiu o orçamento seguinte. Um olhar mais atento pode mostrar que, de fato, 0 que proporcionou o exagerado déficit no ano de 1841-42 não foi a queda da arrecadação, e sim o aumento desproporcional das despesas; enquanto no ano seguinte, o que provocou o déficit foi a queda da arrecadação e não o aumento exagerado dos gastos. Confirma-se, então, a proposição de que as revoltas de 1842 forçaram um aumento de gastos pela província que não era previsto; assim como a geada precipitou uma queda não esperada das receitas do ano orçamentário de 1842-43.

Portanto, retirando os dois anos que obtiveram resultados negativos para orçamento da província por motivos anormais, dos 14 anos orçamentários que também estão contemplados, apenas 5 apresentam déficits. $\mathrm{E}$ mesmo considerando os dois anos (1841-42 e 1842-43), se somadas todas as receitas e delas subtrair todas as despesas, ainda assim, a segunda metade da década de 1830 e a década de 1840 apresentam, no total, superávit.

Vale ressaltar que se optou por apresentar os orçamentos que foram também apresentados por $\operatorname{Costa}^{19} \mathrm{em}$ detrimento dos que aparecem nos Relatórios de Presidentes da Província paulista. Isso porque tais relatórios não nos dão informações para todo o periodo, sendo muito dependente do presidente que estivesse na gestão. Por exemplo, entre os anos orçamentários de 1836-37 e 1847-48, apenas são expostas as receitas e despesas totais para os anos de 1836-37; 1838-39; 1840-41; 1841-42. Vejamos, em comparação com os orçamentos apresentados por Costa, que estão entre parênteses:

\section{Tabela II}

Receita e despesa da Província de São Paulo, em mil réis:

\begin{tabular}{|c|c|c|}
\hline Anos & Receita & Despesa \\
\hline $1836-37$ & $331: 927 \$ 718(338: 289 \$ 390)$ & $143: 154 \$ 341(208: 145 \$ 337)$ \\
\hline $1838-39$ & $248: 215 \$ 284(315: 903 \$ 550)$ & $211: 812 \$ 865(411: 828 \$ 239)$ \\
\hline $1840-41$ & $539: 670 \$ 848(326: 429 \$ 787)$ & $534: 077 \$ 744(203: 086 \$ 924)$ \\
\hline $1841-42$ & $361: 510 \$ 000(405: 418 \$ 878)$ & $502: 902 \$ 245(679: 267 \$ 035)$ \\
\hline
\end{tabular}

Fonte: Relatórios de presidentes da província de São Paulo, anos selecionados.

Mesmo algo diferentes, os orçamentos apresentados pelos presidentes da província paulista nos anos indicados não mudam, no âmbito geral, a conclusão sobre a capacidade provincial em manter equilibrados seus orçamentos, além de produzir superávits em alguns anos, garantindo recursos para investimentos. 
20

Relatório do presidente da província de São Paulo, Manuel Machado Nunes, 1842.

21

Relatório do presidente da província de São Paulo, Manuel Machado Nunes, 1842.

TESSITORE, Viviane. As fontes da riqueza pública. Tributos e administração tributária na Província de São Paulo (1832 - 1892). 1995. $395 f$. Dissertação (Mestrado). Faculdade de Filosofia, Letras e Ciências Humanas, Universidade de São Paulo, São Paulo, 1995. p. 73.
Para o único ano, segundo os relatórios, que apresentou déficit (184142), algumas causas são explicitadas pelo presidente provincial:

Notarei que fui muito cauteloso em orçar as duas rendas principais - a (da barreira) do Rio Negro e a dos dízimos - e a razão é porque tenho motivos para crer que elas diminuirão por alguns anos: a primeira por causa da rebelião da província do Rio Grande do Sul e a segunda por causa do estrago extraordinário que fez a geada nos dois produtos de maior valor da província, o café e o açúcar. 20

Portanto, confirma o que se disse alhures, assim como fez Pivaro. Mesmo assim, no relatório de janeiro de 1842, lê-se:

A estas felizes disposições e à docilidade do povo de São Paulo deve-se em grande parte, o estado de prosperidade que se acham os cofres provinciais. Esta província pode desvanecer-se de ser, porventura, a única que vê acumular-se anualmente um grande saldo depois de satisfeita suas necessidades, que nunca deixam de ser atendidas pelo poder legislativo provincial e por isso é ela também uma das que mais rapidamente tem marchado na estrada dos melhoramentos. 21

Por fim, cabe lembrar de que os orçamentos apresentados pelos relatórios de presidente da província paulista eram feitos em janeiro do ano financeiro corrente, podendo, portanto, haver mudanças até o término do período. Novamente justifica-se, assim, a aceitação dos números apresentados por Costa. Eles foram retirados de uma revisão feita pelo órgão provincial responsável pelas estatísticas financeiras, a Contadoria Provincial, no ano de 1884, pelo contador oficial Pedro Gonçalves Dente.

Uma outra fonte também nos ajuda para apresentar, ao menos em parte, as receitas da Província de São Paulo. Trata-se dos Diários da Tesouraria provincial de São Paulo. Dela pode-se chegar aos seguintes números:

\section{Tabela III}

Receita da Província de São Paulo, em mil réis:

\begin{tabular}{|c|c|}
\hline Anos & Receita \\
\hline $1835-36$ & $206: 883 \$ 461$ \\
\hline $1836-37$ & $307: 810 \$ 078$ \\
\hline $1837-37$ & $374: 214 \$ 127$ \\
\hline $1838-39$ & $370: 138 \$ 303$ \\
\hline $1839-40$ & $318: 294 \$ 212$ \\
\hline $1840-41$ & $456: 958 \$ 990$ \\
\hline $1841-42$ & $234: 065 \$ 663$ \\
\hline
\end{tabular}

Fonte: Diários da Tesouraria provincial de São Paulo, anos selecionados.

Esses dados servem para confirmar que não só a Província de São Paulo garantiu o orçamento equilibrado - mesmo enfrentando ao menos duas ocasiões especiais -, como também conseguiu fazer "caixa" para eventuais novos desequilibrios provocados por situações imprevisiveis. Desta forma, como afirma Tessitore22:

Era preciso arrecadar muito para garantir à província uma infra-estrutura capaz de possibilitar o desenvolvimento de sua economia. A necessidade de ampliar a receita foi insistentemente ligada à idéia de progresso, um progresso a exigir do governo provincial a correspondente ampliação de serviços e, portanto, de despesas. São Paulo, de resto, foi uma das poucas províncias que não recorreu a auxílios financeiros do Governo geral.

Vejamos outros números: 
Tabela IV

Participação aproximada da soma das rendas obtidas pela cobrança de barreiras e pelos direitos de saída na receita total da Província de S. Paulo (em \%):

\begin{tabular}{|c|c|c|c|c|c|}
\hline Anos & Participação & Anos & Participação & Anos & Participação \\
\hline $1835-36$ & 34.5 & $1840-41$ & 28 & $1846-47$ & 40 \\
\hline $1836-37$ & 53.5 & $1841-42$ & 43 & $1847-48$ & 40 \\
\hline $1837-38$ & 50.5 & $1843-44$ & ---- & $1848-49$ & 38 \\
\hline $1838-39$ & 53 & $1844-45$ & 38.5 & $1849-50$ & 53 \\
\hline $1839-40$ & 48 & $1845-46$ & 48 & $1850-51$ & 30.5 \\
\hline
\end{tabular}

Fonte: Costa, Hernani Maia. As barreiras de São Paulo.

Através dos dados, pode-se concluir que a participação das duas maiores fontes orçamentárias da provincia paulista era muito alta, chegando - se somadas -, no ano orçamentário de 1836-37, a mais da metade de toda a receita. Isso significa que, de fato, dada a autonomia referente a estes dois direitos obtida pelas províncias durante a década de 1830, eles serão definitivos no desenvolvimento da economia paulista.

0 destaque feito aos dados referentes às rendas da província paulista durante a segunda metade da década de 1830 e por toda a década de 1840 justifica-se ao tentar mostrar que, sendo tão importantes as duas fontes - direitos de saída e barreiras - era possivel estabelecer um planejamento e controle sobre as finanças da província que independia das mudanças institucionais que, porventura, se originassem no plano central. Isso porque, não obstante a importância da relação entre o governo central e o provincial, era possivel, através do aumento das exportações e da circulação interna -

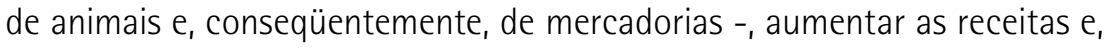
portanto, os investimentos públicos da província de São Paulo. Além disso, mostra que a província de São Paulo tinha possibilidade de arrecadar e de manter seu equilibrio, mais do que a historiografia normalmente admite.

\subsection{Desenvolvimento econômico: as exportações de café.}

Pois bem, até aqui o que se mostrou é bastante diverso do que uma parte da historiografia afirma, ou seja: a autonomia dada às províncias pelo Ato Adicional de 1834 não garantiu a elas a capacidade financeira de manter seus orçamentos equilibrados. ${ }^{23}$ Isso porque a maior parte do "bolo fiscal"

Para a hipótese da incapacidade provincial em manter equilibrado seus orçamentos mesmo durante o período de maior descentralização, ver, principalmente DINIZ, Adalton Franciozo. Centralização política e apropriação de Riqueza: análise das finanças do Império Brasileiro (1821 - 1889). 2002. 245f. e anexos. Tese (Doutorado). Faculdade de Filosofia, Letras e Ciências Humanas, Universidade de São Paulo. São Paulo, 2002

\section{4}

Ver DOHLNIKOFF, Mirian. Construindo o Brasil: unidade nacional e pacto federativo nos projetos das elites (1820 - 1842). 2000. 210f. Tese (Doutorado). Faculdade de Filosofia, Letras e Ciências Humanas, Universidade de São Paulo, São Paulo, 2000; DOHLNIKOFF, Mirian. O Pacto Imperial. Origens do federalismo no Brasil. São Paulo: Ed. Globo, 2005. ficava para o governo central, que não só taxava as atividades mais rentáveis, como importação, como também demonstrava ter um apetite sem igual na transferência de recursos arrecadados nas províncias para o centro. Esta situação tornava as finanças provinciais tão dependentes do governo geral que a saida foi um novo movimento centralizador, portanto contrário à autonomia provincial: o "regresso" conservador de 1840 .

Digo uma parte da historiografia porque os trabalhos recentes feitos por Dohlnikoff 24 (2000 e 2005) mostram que, ao menos para São Paulo, estas afirmações não são procedentes. Ao contrário, a província paulista não só garantiu o seu equilibrio orçamentário, como produziu superávits capazes de bancar os investimentos públicos. Isso porque na divisão entre as rendas gerais e provinciais, algumas que ficaram sob a competência destas últimas eram rentáveis o suficiente para garantir tal situação. As duas competências mais importantes se referiam à cobrança dos direitos de saída (exportação) e sobre a circulação interna de animais, efetivadas nos registros e nas barreiras, como já vimos. 
Nos relatórios dos presidentes provinciais paulistas é comum a defesa da hipótese que o crescimento da produção, transporte e exportação agricola dependiam dos investimentos públicos. Neste caso, vale ressaltar que, considerada como um possivel exagero no argumento - visto que podia representar uma justificativa dos gastos envolvida em retórica política -, a hipótese não descarta o caminho oposto, ou seja, que o crescimento da produção, transporte e exportação agrícola foi precipitada não pelo investimento público, mas sim pelo aumento da demanda internacional. 0 caso do café parece bastante claro. 0 que se defende é que, mesmo com o aumento da demanda internacional estimulando o crescimento da produção de café, os investimentos públicos tiveram participação essencial na viabilidade de tal crescimento.
Além disso, e talvez, principalmente por isso, a capacidade de aumentar a arrecadação era estritamente provincial, dado que as leis referentes à cobrança destas taxas eram definidas nas Assembléias Legislativas provinciais; e os investimentos em infra-estrutura que poderiam garantir tal aumento na arrecadação também o eram. Portanto, estava no processo político interno da província, e não do Império, a possibilidade de garantir o desenvolvimento econômico e, conseqüentemente, o aumento da arrecadação. Então, o maior efeito que as mudanças institucionais referentes à centralização e descentralização político-administrativa ocorridas no país provocaram na província de São Paulo está relacionado ao Ato Adicional e à relativa autonomia que garantiu às províncias. E não, como muitos afirmam, na centralização exagerada ocorrida a partir de 1840. 0 que se defende aqui é que tal projeto de centralização não significou a retirada da autonomia fiscal-orçamentária das províncias, o que o caso paulista confirma. Portanto, o que este trabalho defende é que a ascensão da riqueza paulista durante a década de 1840 deveu-se mais à maneira que a província usou a autonomia, garantida por lei, para, através de legislações específicas à provincia e, conseqüentemente, liberdade relativa de se re-arranjar do ponto de vista institucional, determinar sua arrecadação, seus investimentos públicos e o crescimento econômico. ${ }^{25}$

Uma outra abordagem pode confirmar a hipótese que, mesmo em uma situação na qual a maior parte dos recursos ficava nas mãos do governo central, a província paulista não amargou um ambiente de penúria econômica; ao contrário, soube aproveitar as lacunas deixadas pela lei e garantir seus orçamentos equilibrados, algumas vezes superavitários (como vimos), além de viver um período de crescimento econômico. Alguns dados nos ajudam a enxergar tal situação:

\section{Tabela V}

Exportações de açúcar e café pelo porto de Santos, em arrobas:

\begin{tabular}{|c|c|c|}
\hline Anos & Açúcar & Café \\
\hline $1836-37$ & 433.268 & 87.659 \\
\hline $1837-38$ & 297.041 & 97.751 \\
\hline $1838-39$ & 490.018 & 113.965 \\
\hline $1839-40$ & 570.779 & 136.524 \\
\hline $1840-41$ & 533.142 & 184.970 \\
\hline $1841-42$ & 193.677 & 53.260 \\
\hline $1842-43$ & 162.771 & 6.571 \\
\hline $1843-44$ & 222.306 & 112.128 \\
\hline $1844-45$ & 495.305 & 190.850 \\
\hline $1845-46$ & 548.742 & 207.730 \\
\hline $1846-47$ & 609.095 & 244.338 \\
\hline $1847-48$ & 414.230 & 246.893 \\
\hline $1848-49$ & 278.823 & 225.588 \\
\hline $1849-50$ & 269.389 & 130.681 \\
\hline $1850-51$ & 344.904 & 470.054 \\
\hline
\end{tabular}

Fonte: Livro das exportações da Barreira de Cubatão, entrada de Santos.

Como vemos, as exportações de café pelo porto de Santos registraram, durante os 15 anos citados, aumento de pouco mais de 500\%. Já os direitos de saída cresceram, no mesmo periodo, aproximadamente $250 \%$. Vejamos: 
Tabela VI

Direitos de saída arrecadados pela província de São Paulo, em mil réis:

\begin{tabular}{|c|c|c|c|}
\hline Ano fiscal & Arrecadação & Ano fiscal & Arrecadação \\
\hline $1835-36$ & $31: 351 \$ 648$ & $1843-44$ & $58: 955 \$ 81$ \\
\hline $1836-37$ & $49: 282 \$ 769$ & $1844-45$ & $83: 107 \$ 403$ \\
\hline $1837-38$ & $78: 597 \$ 267$ & $1845-46$ & $90: 555 \$ 000$ \\
\hline $1838-39$ & $100: 396 \$ 780$ & $1846-47$ & $96: 809 \$ 631$ \\
\hline $1839-40$ & $93: 189 \$ 983$ & $1847-48$ & $79: 954 \$ 088$ \\
\hline $1840-41$ & $66: 999 \$ 977$ & $1848-49$ & $57: 089 \$ 514$ \\
\hline $1841-42$ & $45: 624 \$ 359$ & $1849-50$ & $81: 224 \$ 078$ \\
\hline $1842-43$ & $53: 071 \$ 675$ & $1850-51$ & $123: 842 \$ 458$ \\
\hline
\end{tabular}

Fonte: Costa, Hernani Maia. As barreiras de São Paulo.

Devemos lembrar que os dados são referentes ao total recolhido sobre as exportações na província paulista e não só sobre as exportações feitas por Santos. Também não considera as variações de preço do café, ano a ano. Porém, dos 15 anos comparados, 9 apresentam relações positivas entre exportação de café e direitos de saída. Apenas 6 não apresentam, mesmo que, em nenhum dos casos, os números sejam proporcionais; ou seja, a queda na arrecadação não é diretamente proporcional à queda do volume exportado. Seria improvável que fosse, dadas as variações de preços possiveis entre um ano e outro. Se usarmos o câmbio entre libras e mil-réis como parâmetro, podemos concluir que o aumento das exportações de café, dependendo do valor do câmbio, não significava aumento das receitas oriundas dos direitos de saída. Em outros termos, o preço do café poderia variar para baixo em um nível maior que o aumento das exportações. Aumentava o volume de exportação, mas não o valor total das exportações 26 . Vejamos:

0 ano fiscal de 1842-43 apresenta uma queda muito acentuada na exportação de café e açúcar pelo porto de Santos devido à geada que comprometeu parte da produção e também aos conflitos que ocorriam no interior da provincia paulista. Porém, a queda na arrecadação de direitos de saída não reflete, na mesma proporção, os problemas citados. É possível supor um aumento de preços temporário devido aos problemas na produção, assim como o aumento na participação de outros produtos na composição da arrecadação de direitos de saída.

\section{Tabela VII}

Paridade Cambial entre mil-réis e a libra esterlina

\begin{tabular}{|c|c|}
\hline Ano & mil réis por libra \\
\hline 1835 & $6 \$ 115$ \\
\hline 1840 & $7 \$ 742$ \\
\hline 1845 & $9 \$ 435$ \\
\hline 1850 & $8 \$ 348$ \\
\hline
\end{tabular}

Fonte: IBGE, séries estatísticas retrospectivas, 1987, vol. 3.

Os dados referentes à paridade entre mil-réis e libra nos mostra claramente uma tendência de desvalorização da moeda nacional. Portanto, estímulo à exportação. Porém, outros dados podem esclarecer o porque do aumento das exportações em volume não significar, durante a década de 1840, aumento, na mesma proporção, da arrecadação:

\section{Tabela VIII}

Volume (em sacas) das exportações brasileiras e preço (em libras) do café:

\begin{tabular}{|c|c|c|}
\hline Período & volume (mil sacas) & preços (libras por saca) \\
\hline $1831-40$ & 9.744 & 2,21 \\
\hline $1841-50$ & 16.677 & 1,39 \\
\hline $1851-60$ & 26.252 & 1,89 \\
\hline
\end{tabular}

Fonte: Buescu, Mircea. Evolução econômica do Brasil, citado por Almeida, Paulo Roberto. Formação da diplomacia econômica no Brasil. São Paulo: Ed. Senac, 2001.

Segundo os dados, o preço do café, em libras, durante a década de 1840 foi, em média, o menor das três décadas contempladas. Uma simples comparação pode, novamente, nos levar a algumas conclusões: 
Tabela IX

Câmbio e preço do café, em libras e mil réis:

\begin{tabular}{|c|c|c|c|}
\hline Ano & $\begin{array}{c}\text { Preço médio (em } \\
\text { Ł,por saca) }\end{array}$ & câmbio & preço (réis) \\
\hline 1835 & 2.21 & $6 \$ 115$ & $13 \$ 453$ \\
\hline 1840 & 1.39 & $7 \$ 742$ & $10 \$ 838$ \\
\hline 1845 & 1.39 & $9 \$ 435$ & $13 \$ 210$ \\
\hline 1850 & 1.39 & $8 \$ 348$ & $11 \$ 687$ \\
\hline
\end{tabular}

Fonte: IBGE, séries estatísticas retrospectivas, 1987, vol. 3.

Portanto, a variação de preço é significativa a ponto de não permitir uma relação positiva entre aumento do volume de exportações e a arrecadação de direitos de saída. É claro que, pelos números apresentados aqui, não se está querendo estipular o exato preço do café, até porque se está usando uma média. Porém, estes números podem nos dar a tendência - queda ou ascensão - dos preços do café.

Vale lembrar, também, que os direitos de saída não incluem apenas o café, mas todos os produtos exportados. Contudo, em um confronto entre os dados referentes à exportação, pelo porto de Santos, de açúcar e de café - os dois principais produtos da província paulista durante a década de 1840 -, pode-se concluir que a tendência é de queda do volume de açúcar e crescimento do volume de café (Ver Tabela 5).

As variações na exportação de açúcar e café não seguem uma relação positiva, porém, mesmo que no fim do periodo (1851) a soma das exportações de açúcar seja significativamente maior que a soma das exportações de café, percebemos a tendência de reversão, já que no ano financeiro de 1850-51 a exportação de café já é maior que a de açúcar. Sobre isso, Pivaro27 (1985: 99) afirma:

PÍVARO, Hilda. 0 processo de recuperação da economia paulista (1765 - 1850). 1985. 3 vols. Tese (Doutorado). Faculdade de Filosofia, Letras e Ciências Humanas, Universidade de São Paulo, São Paulo, 1985. p.99.

\section{8}

0 imposto sobre exportação, tanto para fora da provincia como para fora do pais, obedecia a seguinte determinação: $5 \%$ sobre manufaturados e 10\% sobre não-manufaturados. Estes valores foram definidos em 1835, logo após a criação da Assembléia Provincial. Em 1840, tais impostos foram classificados como direitos de saída da provincia e se tornaram a maior fonte de renda de São Paulo.
Através das evidências, poderíamos concluir observando que a década de 1840 foi decisiva para a economia paulista, pois marca a substituição progressiva da lavoura canavieira pela cafeeira, confirmada a partir do exercício de 1850-51. Quando o café tornou-se o principal gênero agrícola de exportação, deixando o açúcar na 2a posição e, em $3^{\circ}$ lugar o fumo, em proporções menores de volumes exportados. Era o início do domínio incontestável do café.

Se, ao que foi apresentado, somar-se novos dados sobre a exportação a partir de Santos, percebe-se a importância do café para as receitas paulistas 28 :

Analisando a tabela 6 , se confrontarmos os números totais de arrecadação sobre os direitos de saída, notaremos que 1838-39 foi fantástico para a província, representando o $2^{\circ}$ maior entre os 16 anos apresentados. Apenas no orçamento de 1850-51 é que a arrecadação sobre os direitos de saída foi maior. Já a arrecadação sobre direitos de saída do ano orçamentário de 1842-43 foi a $4^{\text {a }}$ pior entre todos os apresentados. Apenas nos anos de 1835-36, de 1836-37 e de 1841-42, os direitos de saída arrecadados foram mais baixos que no ano orçamentário de 1842-43. Portanto, este ano foi péssimo para a arrecadação. Desta forma, não se pode afirmar nenhuma relação entre arrecadação de direitos de saída e maior descentralização ou centralização político-administrativa no país. Vejamos, usando os dados referentes aos anos de 1838-39, 1842-43 e 1844-45. 
Tabela X

Participação da arrecadação sobre o café exportado pelo porto de Santos (em mil réis e em \% aproximada):

\begin{tabular}{|c|c|c|c|}
\hline Ano fiscal & Arrecadação Total & Arrecadação sobre o café & Participação do café \\
\hline $1838-39$ & $27: 703 \$ 843$ & $14: 330 \$ 755$ & 51 \\
\hline $1842-43$ & $12: 304 \$ 110$ & $5: 657 \$ 826$ & 46 \\
\hline $1844-45$ & $20: 887 \$ 446$ & $7: 960 \$ 851$ & 38 \\
\hline
\end{tabular}

Fonte: Livro da Receita do dízimo provincial da Vila de Santos e Mapa demonstrativo do dízimo provincial da Alfândega de Santos.

0 que se pode é confirmar que nos direitos arrecadados sobre exportação pelo porto de Santos a participação do café era alta, mesmo em anos onde o volume de café exportado era menor que o de açúcar. Em outras palavras, o café, mesmo exportado em quantidades menores que o açúcar rendia arrecadação maior. Daí o estímulo em trocar a produção de açúcar pela de café, e, conseqüentemente, a tendência de queda do primeiro em benefício do segundo produto.

\section{Conclusão}

A divisão das atribuições fiscais entre o governo imperial e as provincias feita pelo Ato Adicional, em 1834, não foi modificada durante o processo de centralização do poder político e administrativo que se seguiu ao período do "avanço" liberal. Dessa forma, os direitos adquiridos pelas províncias não se alteraram, permanecendo aqueles que foram determinados pela descentralização de 1834.

Isso significa que, não obstante a maior parte das rendas fiscais ser de direito do governo central, às provincias sobraram alguns direitos que possibilitavam relativa autonomia no que tange a arrecadação, os gastos e os investimentos. No caso de São Paulo, foi possivel à província viver um período de crescimento - fosse na arrecadação, fosse na produção e exportação agrícola.

Confirmando, o que vimos é que, segundo os dados, a província de São Paulo apresentou crescimento econômico independente das variações institucionais que ocorriam no país relacionadas à centralização do poder político. Portanto, não é possível afirmar, ao menos no caso de São Paulo, que a estrutura fiscal brasileira durante o Império era tão favorável ao governo central que impedia qualquer autonomia provincial. Esse argumento está na origem da hipótese que propõe uma interpretação acerca do processo político do Império por meio do seguinte argumento: dada a incapacidade das provincias em manterem equilibrados seus respectivos orçamentos e impedidas de qualquer crescimento autônomo, a única saída era a centralização do poder em mãos do governo imperial. Ao menos no caso paulista, essa hipótese não é confirmada pelos dados, o que nos lança novos desafios em busca do entendimento da complexa relação entre as províncias e o governo central - ou entre as forças centrifugas e centripetas - em meados do século XIX; ou seja, durante o período capital para a construção do Estado Nacional brasileiro.

Recebido para publicação em janeiro de 2007

Aprovado em março de 2007 